geography (distance from home to hospital), and even hospital administrative factors (prioritization of patients in a crowded ward). Possible varying practice among hospitals is unlikely to have influenced the main results, because we found no significant hospital-treatment interaction.
Håvard Ove Skjerven, M.D.

Kai-Håkon Carlsen, M.D., Ph.D.

Karin C. Lødrup Carlsen, M.D., Ph.D.

Oslo University Hospital

Oslo, Norway

h.o.skjerven@medisin.uio.no

Since publication of their article, the authors report no further potential conflict of interest.

DOI: 10.1056/NEJMc1308964

\title{
Antithrombotic Therapy and Invasive Procedures
}

TO THE EDITOR: Baron et al. (May 30 issue) ${ }^{1}$ make important suggestions in their review article; however, we propose that quantitative assessment of iatrogenic bleeding hazards must be considered as well as thrombosis prevention. ${ }^{1} \mathrm{Al}-$ though $\mathrm{CHA}_{2} \mathrm{DS}_{2}-\mathrm{VASc}$ scoring for atrial fibrillation is mentioned, the Hypertension, Abnormal Renal/Liver Function, Stroke, Bleeding History or Predisposition, Labile INR, Elderly, Drugs/Alcohol Concomitantly (HAS-BLED) score for bleeding has also been validated. ${ }^{2}$ Both scores calculate estimated annual risks and benefits and hence can guide future therapy.

Among the diverse causes of major bleeding outcomes associated with antithrombotic agents are periprocedural, intracranial, and gastrointestinal causes. ${ }^{3}$ Although few therapies can treat and prevent the first two factors, data from a large, randomized trial show that proton-pump inhibitors are safe for concomitant use with antithrombotic agents. ${ }^{4}$ Given the shorter time frame in which medications are being withheld for procedures, the absolute thrombotic or bleeding risks can be overstated; however, bleeding (and its consequences) remains an important iatrogenic issue. Populations globally are also being treated increasingly with combinations of antithrombotic therapies and medications such as nonsteroidal antiinflammatory drugs (NSAIDs), which can intensify such bleeding risks. ${ }^{5}$ Hence, further quantitative research, including validation of cause-specific bleeding scores associated with antithrombotic agents, is paramount to guide clinical management.

\footnotetext{
Ajay M. Verma, M.R.C.P.

Kettering General Hospital

Kettering, United Kingdom

Neeraj Bhala, M.R.C.P.

Queen Elizabeth Hospital

Birmingham, United Kingdom

nijbhala@doctors.org.uk
}

No potential conflict of interest relevant to this letter was reported.

1. Baron TH, Kamath PS, McBane RD. Management of antithrombotic therapy in patients undergoing invasive procedures. N Engl J Med 2013;368:2113-24.

2. Lip GY, Frison L, Halperin JL, Lane DA. Comparative validation of a novel risk score for predicting bleeding risk in anticoagulated patients with atrial fibrillation: the HAS-BLED (Hypertension, Abnormal Renal/Liver Function, Stroke, Bleeding History or Predisposition, Labile INR, Elderly, Drugs/Alcohol Concomitantly) score. J Am Coll Cardiol 2011;57:173-80.

3. Bhala N, Taggar JS, Rajasekhar P, Banerjee A. Anticipating and managing bleeding complications in patients with coronary stents who are receiving dual antiplatelet treatment. BMJ 2011; 343: $\mathrm{d} 4264$.

4. Bhatt DL, Cryer BL, Contant CF, et al. Clopidogrel with or without omeprazole in coronary artery disease. $\mathrm{N}$ Engl J Med 2010;363:1909-17.

5. Hallas J, Dall M, Andries A, et al. Use of single and combined antithrombotic therapy and risk of serious upper gastrointestinal bleeding: population based case-control study. BMJ 2006;333:726.

DOI: $10.1056 / N E J M c 1308259$

TO THE EDITOR: The review article by Baron et al. does not address the clinical safety and efficacy of new antithrombotic agents in patients with cancer who are undergoing surgical procedures. A sizable number of patients with cancer undergo surgery or procedures with local or regional anesthesia. Trials of oral direct thrombin inhibitors and oral factor Xa inhibitors have enrolled less than $5 \%$ of patients with cancer. ${ }^{1}$ Because of a lack of data, the American Society of Clinical Oncology recommends against the use of new oral anticoagulants (for prevention and treatment) in patients with cancer. ${ }^{2}$ These patients also frequently require anesthesia to undergo long invasive procedures. The American Society of Regional Anesthesia and Pain Medicine recommends cautious use of these agents in patients undergoing neuraxial anesthesia. ${ }^{3}$ The lack of both efficacy data and an antidote for reversibility of bleeding should prompt clinicians to be cautious while administering the new anticoagulants in 
patients with cancer who are likely to undergo invasive procedures.

S. Wamique Yusuf, M.B., B.S.

Ali Zalpour, Pharm.D.

University of Texas M.D. Anderson Cancer Center Houston, TX

syusuf@mdanderson.org

No potential conflict of interest relevant to this letter was reported.

1. Adam SS, McDuffie JR, Ortel TL, Williams JW Jr. Comparative effectiveness of warfarin and new oral anticoagulants for the management of atrial fibrillation and venous thromboembolism: a systematic review. Ann Intern Med 2012;157:796-807.

2. Lyman GH, Khorana AA, Kuderer NM, et al. Venous thromboembolism prophylaxis and treatment in patients with cancer: American Society of Clinical Oncology clinical practice guideline update. J Clin Oncol 2013;31:2189-204.

3. Horlocker TT, Wedel DJ, Rowlingson JC, et al. Regional anesthesia in the patient receiving antithrombotic or thrombolytic therapy: American Society of Regional Anesthesia and Pain Medicine Evidence-Based Guidelines (Third Edition). Reg Anesth Pain Med 2010;35;64-101.

DOI: 10.1056/NEJMc1308259

TO THE EDITOR: The panel on the 2012 guidelines of the American College of Chest Physicians (ACCP) on periprocedural antithrombotic therapy concluded that the quality of evidence for bridging therapy, even in patients with "high" thrombotic risk, was weak enough to warrant only grade $2 \mathrm{C}$ recommendations. ${ }^{1}$ This is the weakest recommendation possible and supports the suggested (not required) use of bridging therapy in any patient group. Two ongoing placebocontrolled trials (not one, as stated by Baron and colleagues) are investigating bridging therapy. These trials are Bridging Anticoagulation in Patients Who Require Temporary Interruption of Warfarin Therapy for an Elective Invasive Procedure or Surgery (ClinicalTrials.gov number, NCT00786474) and A Double Blind Randomized Control Trial of Post-Operative Low Molecular Weight Heparin Bridging Therapy Versus Placebo Bridging Therapy for Patients Who Are at High Risk for Arterial Thromboembolism (NCT00432796).

With respect to restarting therapy, most guidelines recommend restarting anticoagulation within 24 hours after a procedure involving a low risk of bleeding. Waiting 48 hours, as Baron et al. suggest, may expose a patient to the risk of thromboembolism. For procedures involving a high risk of bleeding, waiting 48 to 72 hours or considering a stepwise increase in antithrombotic therapy is suggested. ${ }^{2}$

Table 4 of the article by Baron et al. incor- rectly recommends the use of anti-factor $\mathrm{Xa}$ "antibody" levels to monitor treatment with lowmolecular-weight heparin, rivaroxaban, and apixaban. Table 2 includes content from Table 1 in the 2012 ACCP guidelines on periprocedural antithrombotic agents and should cite this reference. ${ }^{1}$

Alex C. Spyropoulos, M.D.

Hofstra University School of Medicine,

North Shore-Long Island Jewish Health System Manhasset, NY

Thomas L. Ortel, M.D., Ph.D.

Duke University Medical Center

Durham, NC

thomas.ortel@duke.edu

Dr. Ortel reports receiving research support from Eisai. No other potential conflict of interest relevant to this letter was reported.

1. Douketis JD, Spyropoulos AC, Spencer FA, et al. Perioperative management of antithrombotic therapy: Antithrombotic Therapy and Prevention of Thrombosis, 9th ed: American College of Chest Physicians Evidence-Based Clinical Practice Guidelines. Chest 2012;141:Suppl:e326S-e350S. [Erratum, Chest 2012; 141:1129.]

2. Spyropoulos AC, Douketis JD. How I treat anticoagulated patients undergoing an elective procedure or surgery. Blood 2012;120:2954-62.

DOI: $10.1056 /$ NEJMc1308259

TO THE EDITOR: Baron et al. offer some very practical advice for treating patients who are receiving warfarin and who require bridging anticoagulation therapy for procedures. Unfortunately, some of their advice could lead to undesirable outcomes. Patients with deficiencies in protein C, $\mathrm{S}$, or both or dysproteinemia of either protein $\mathrm{C}$ or $S$ require full therapeutic anticoagulation with heparin (or a low-molecular-weight heparin) before initiation of warfarin; otherwise, they are at risk for the development of the prothrombotic state described as warfarin-induced skin necrosis. ${ }^{1,2}$ It is important to be aware of this when recommending the postoperative timing of initiation of heparin (or a low-molecular-weight heparin) and warfarin.

Although typically it takes 5 to 7 days of warfarin therapy to achieve anticoagulation, the halflife of prothrombin is approximately 72 hours, and patients with an international normalized ratio (INR) of more than 1.9 do not receive anticoagulation therapy immediately. To avoid a period of inadequate anticoagulation, the bridging heparin should not be discontinued when the INR is at a therapeutic level, but rather it should be continued at least 24 and preferably 48 hours after the INR is more than 1.9. 
Charles A. Bomzer, M.D.

Aurora Cancer Care

Milwaukee, WI

cbomzer@execpc.com

No potential conflict of interest relevant to this letter was reported.

1. McGehee WG, Klotz TA, Epstein DJ, Rapaport SI. Coumarin necrosis associated with hereditary protein C deficiency. Ann Intern Med 1984;101:59-60.

2. Sallah S, Abdallah JM, Gagnon GA. Recurrent warfarininduced skin necrosis in kindreds with protein $S$ deficiency. Haemostasis 1998;28:25-30.

DOI: 10.1056/NEJMc1308259

TO THE EDITOR: The article by Baron et al. contains some inconsistencies. The authors propose continuation of antithrombotic agents in patients undergoing cataract surgery and receiving intraocular injections, since these procedures are considered to be associated with a low risk of bleeding $(<1.5 \%)$. Periorbital and vitreoretinal surgeries are classified as procedures associated with a high risk of bleeding ( $>1.5 \%)$ and, therefore, in patients who are at low risk for thrombotic events, anticoagulation therapy may be temporarily discontinued without the use of bridging therapy, whereas for selected high-risk patients, bridging therapy is strongly recommended (Table S1 in the Supplementary Appendix of the article, available at NEJM.org). However, this statement contradicts their proposal that procedures that can result in intraocular bleeding are associated with high risk and classified as major. Likewise, prospective cohort studies in cataract surgery have shown an incidence of clinically important bleeding of up to $3 \% .{ }^{1}$ Peribulbar anesthesia ${ }^{2}$ and transconjunctival sutureless vitrectomies ${ }^{3}$ may be safe in these patients. Finally, one editorial has suggested that the risk of a cardiovascular event among patients in whom anticoagulant and antiplatelet agents are discontinued is higher than the risk of bleeding during ocular surgery among patients who continue to receive these drugs. ${ }^{4}$

Andrzej Grzybowski, M.D., Ph.D.

University of Warmia and Mazury

Olsztyn, Poland

ae.grzybowski@gmail.com

Francisco J. Ascaso, M.D., Ph.D.

University Clinic Hospital

Zaragoza, Spain

No potential conflict of interest relevant to this letter was reported.

1. Douketis JD, Spyropoulos AC, Spencer FA, et al. Perioperative management of antithrombotic therapy: Antithrombotic Ther- apy and Prevention of Thrombosis, 9th ed: American College of Chest Physicians Evidence-Based Clinical Practice Guidelines. Chest 2012;141:Suppl:e326S-e350S. [Erratum, Chest 2012;141: 1129.]

2. Passemard M, Koehrer P, Juniot A, Bron AM, Creuzot-Garcher C. Maintenance of anticoagulant and antiplatelet agents for patients undergoing peribulbar anesthesia and vitreoretinal surgery. Retina 2012;32:1868-73.

3. Malik AI, Foster RE, Correa ZM, Petersen MR, Miller DM, Riemann CD. Anatomical and visual results of transconjunctival sutureless vitrectomy using subconjunctival anesthesia performed on select patients taking anticoagulant and antiplatelet agents. Retina 2012;32:905-11.

4. Fung AT, Hunyor AP. To bleed or clot? Clin Experiment Ophthalmol 2013;41:315-7.

DOI: 10.1056/NEJMc1308259

THE AUTHORS REPLY: In reply to the comments by Verma and Bhala: better predictors of bleeding are needed in patients receiving antithrombotic agents and NSAIDs, and data to support management recommendations are lacking. The comment regarding proton-pump inhibitors relates to spontaneous bleeding, which was not our focus.

With regard to the comments by Yusuf and Zalpour: we appreciate the citation to the American Society of Clinical Oncology recommendations and agree that treatment with a periprocedural antithrombotic agent is also important in patients undergoing neuraxial anesthesia. ${ }^{1}$

With regard to the comments by Spyropoulos and Ortel: the risk of periprocedural bleeding is triple that of the risk of thromboembolism; fulldose parenteral anticoagulants administered for 24 hours or less increase bleeding risk. ${ }^{2}$ Therefore, we withhold full-dose parenteral anticoagulants for 48 hours unless the risk of bleeding is low. Anti-factor Xa assays can be used for monitoring of anticoagulant effects. ${ }^{3}$ We apologize for not citing the ACCP guidelines (reference 2 of our article) in Table 2.

Bomzer describes the risk of warfarin-induced skin necrosis due to deficiencies in protein $\mathrm{C}, \mathrm{S}$, or both or dysproteinemia; however, this condition is rare. In the general population, the prevalence of this condition due to deficiency in protein $C$ is 1 case per 200 to 500 persons, and the prevalence of this condition due to deficiency in protein $S$ is 1 case per 800 persons. Heparin bridging during warfarin initiation appears to be warranted in these patients. However, universal bridging therapy for atrial fibrillation alone (estimated U.S. prevalence, 2.7 million to 6.1 million cases) would greatly increase adverse events such as heparin-induced thrombocytopenia. New 
anticoagulants may prevent warfarin-induced skin necrosis but cannot be recommended yet.

Finally, in reply to Grzybowski and Ascaso: the use of antithrombotic agents in ocular surgery remains highly controversial. The stated bleeding rate of $3 \%$ is excessive in modern cataract surgery. This avascular procedure, which is frequently performed with topical anesthesia, avoids potential retrobulbar hemorrhage due to retrobulbar anesthesia. However, retrobulbar anesthesia is frequently used in vitreoretinal surgery. Catastrophic bleeding during vitreoretinal surgery can be due to choroidal hemorrhage and neovascularization in proliferative retinal diseases. Bleeding after sutureless vitreoretinal surgery may be uncontrolled, since hypotonia in an open eye prevents tamponade.
Todd H. Baron, M.D.

Patrick S. Kamath, M.D.

Robert D. McBane, M.D.

Mayo Clinic

Rochester, MN

baron.todd@mayo.edu

Since publication of their article, the authors report no further potential conflict of interest.

1. Garcia DA, Baglin TP, Weitz JI, Samama MM. Parenteral anticoagulants: Antithrombotic Therapy and Prevention of Thrombosis, 9th ed: American College of Chest Physicians EvidenceBased Clinical Practice Guidelines. Chest 2012;141:Suppl: e24S-e43S. [Erratum, Chest 2012;141:1369.]

2. Tafur AJ, McBane R II, Wysokinski WE, et al. Predictors of major bleeding in peri-procedural anticoagulation management. J Thromb Haemost 2012;10:261-7.

3. Samama MM, Contant G, Spiro TE, et al. Laboratory assessment of rivaroxaban: a review. Thromb J 2013;11:11.

DOI: 10.1056/NEJMc1308259

\section{Case Reports of PML in Patients Treated for Psoriasis}

TO THE EDITOR: In their letters about patients who were receiving oral dimethyl fumarate for the treatment of psoriasis, Ermis et al. ${ }^{1}$ and van Oosten et al. ${ }^{2}$ (April 25 issue) state that progressive multifocal leukoencephalopathy (PML) had been diagnosed in two patients. Dimethyl fumarate is the active ingredient in Fumaderm, which since 1994 has been registered for the treatment of psoriasis in Germany. Leukopenia and lymphopenia are known adverse effects of such therapy.

The summary of product characteristics for Fumaderm and current guidelines recommend that in all patients receiving the drug, a differential blood count should be obtained every 2 to 3 months and the drug should be terminated if the leukocyte count is below 3000 per cubic millimeter or the lymphocyte count is below 500 per cubic millimeter. ${ }^{3,4}$ In the safety database of the German drug agency (BfArM), which covers more than 180,000 patient-years of Fumaderm exposure, no cases of PML have been documented in patients in whom these rules were applied. In contrast, in all cases of PML observed in association with therapy with dimethyl fumarate, physicians have not adequately treated lymphopenia. The two patients who are described in the Journal both had lymphocyte counts below the threshold of 500 per cubic millimeter for more than 2 years. It appears, therefore, that these cases of PML occurred after long-standing, severe lymphopenia, which has been identified as a primary risk factor for PML. ${ }^{5}$

Ulrich Mrowietz, M.D.

University Medical Center Schleswig-Holstein

Kiel, Germany

umrowietz@dermatology.uni-kiel.de

Kristian Reich, M.D.

Dermatologikum Hamburg

Hamburg, Germany

Dr. Mrowietz reports receiving lecture fees and travel expenses from AbbVie, Almirall Hermal, BASF, Biogen Idec, Celgene, Centocor, Forward Pharma, Janssen, Leo Pharma, Medac, MSD, Miltenyi Biotec, Novartis, Pfizer, VBL Therapeutics, and XenoPort, receiving educational grants from AbbVie, Biogen Idec, Janssen, Novartis, and Pfizer, and participating in clinical trials sponsored by AbbVie, Almirall Hermal, Amgen, Biogen Idec, Celgene, Centocor, Eli Lilly, Forward Pharma, Janssen, Leo Pharma, Medac, MSD, Novartis, Pfizer, Teva, and VBL Therapeutics. Dr. Reich reports receiving travel expenses and lecture fees from AbbVie, Almirall Hermal, Basilea, Biogen Idec, Celgene, Centocor, Forward Pharma, Janssen, Leo Pharma, Medac, MSD, Miltenyi Biotec, Novartis, Ocean Pharma, Pfizer, and UCB, receiving educational grants from AbbVie, Biogen Idec, Janssen, MSD, Novartis, and Pfizer, and participating in clinical trials sponsored by AbbVie, Almirall Hermal, Amgen, Biogen Idec, Celgene, Centocor, Eli Lilly, Forward Pharma, Galderma, Janssen, Leo Pharma, Medac, MSD, Novartis, and Pfizer. No other potential conflict of interest relevant to this letter was reported.

1. Ermis U, Weis J, Schulz JB. PML in a patient treated with fumaric acid. N Engl J Med 2013;368:1657-8.

2. van Oosten BW, Killestein J, Barkhof F, Polman CH, Wattjes MP. PML in a patient treated with dimethyl fumarate from a compounding pharmacy. N Engl J Med 2013;368:1658-9. [Erratum, N Engl J Med 2013;368:1950.]

3. Rostami Yazdi M, Mrowietz U. Fumaric acid esters. Clin Dermatol 2008;26:522-6.

4. Nast A, Boehncke WH, Mrowietz U, et al. S3 - guidelines 